\title{
Aby WARBURg e WALTER BeNJAMIN: A LEgIBILIDADE DA MEMÓRIA
}

\section{ABY WARBURG AND WALTER BENJAMIN: THE READABILITY OF MEMORY}

\author{
Maria João Cantinho* \\ mjcantinho@gmail.com
}

RESUMO: Apenas após a década de 90, a obra de Aby Warburg foi "revisitada" por autores que fizeram um trabalho notável na sua divulgação e também na pesquisa do seu arquivo. De uma actualidade bem pertinente, os conceitos warburgianos são considerados hoje um importante marco na viragem da historiografia, sobretudo aplicada a temas como a fotografia, o cinema e a história de arte. A ideia de uma "ciência sem nome", aludindo a uma pretensa unidade da ciência, visa uma interdisciplinaridade que é hoje um dos conceitos caros às ciências humanas. Por outro lado, Warburg partilhava com Benjamin uma historiografia ao arrepio do historicismo e de uma visão redutora da história. É precisamente a partir do conceito de imagem e da "imagem em movimento" e também da ideia de "vida póstuma das imagens" (Nachleben) que Warburg parte, para definir a abertura da historiografia.

PALAVRAS-CHAVE: Historiografia, imagem, Pathosformel, Mnemosyne

ABSTRACT: After the 1990's decade, the work of Aby Warburg was "revisited" by authors that made a remarkable work in his propagation and also they're contributions for the research of his archive. With a pertinent actuality, the Warburgian's concepts are considered, in our days, an important mark in the turning of historiography, especially when applied to subjects such as photography, cinema and art history. The idea of a "Nameless Science", alluding to a supposed unity of science, aims at a interdisciplinary view, which is now so valued in the humane sciences. On the other hand, Warburg shared with Benjamin a historiography that shivers from historiography and from a reductive view of history itself. It is precisely from this concept of image and of "moving image" and also from the idea of the "image's posthumous life" (Nachleben) that Warburg sets from to define the openness of historiography.

KEYWORDS: Historiography, Image, Pathosformel, Mnemosyne.

\section{Aby Warburg: um "sismógrafo do seu tempo"}

Ao longo destes últimos anos, a proliferação de estudos sobre Aby Warburg, historiador de arte, tem vindo a demonstrar a singularidade da obra e do pensamento deste autor, cujo âmbito não se restringe à história de arte, mas possui um alcance muito mais vasto. O seu contributo foi essencialmente o de desenvolver um conjunto de conceitos e de instrumentos que são actualmente utilizados pelas mais diversas áreas, nomeadamente as artes, com destaque para a fotografia e cinema, a antropologia, os estudos sobre a imagem, a iconografia, etc. Ressaltemos em Warburg os aspectos decisivos que produziram uma visão articulada e complexa da cultura, construída a partir de conceitos operatórios que lhe conferem organicidade, tais como "Nachleben", "Pathosformel" e "Mnemosyne". Estes possuem um carácter dinâmico e operatório, no sentido em que "Nachleben" não se resume

\footnotetext{
* Professora Auxiliar do lade e pesquisadora do CFUL (Centro de Filosofia da Universidade de Lisboa) e do Centre d'Études Juives (Sorbonne)
} 
a uma mera sobrevivência estática, tal como "Pathosformel" e "Mnemosyne" não são, da mesma forma, instâncias formais vazias, conservadoras e reprodutivas, no âmbito dos cânones da visão tradicional da história de arte e da iconografia. Ao invés, elas constituemse como instâncias de "repetição", com afinidades no modo como Deleuze usou o conceito de repetição, na articulação com a questão da produção da diferença, na sua obra Diferença e Repetição. Podemos, relembrar uma relação de afinidade com a morfologia goethiana ${ }^{1} \mathrm{e}$ os seus estudos sobre as formas, bem como os estudos de Cassirer sobre o mesmo tema.

Nascido em Hamburg, em 1866, Aby Warburg morreu em 1929. Oriundo de uma família abastada de banqueiros judeus, cuja origem remonta ao século XVIII, toda a sua existência de Privatgelehrter ${ }^{2}$ foi garantida pela fortuna da família. Numa carta dirigida ao seu irmão Max Warburg, datada de 30 de Junho de 1900, Aby escrevia que "o capitalismo pode também levar a cabo um trabalho de reflexão com o mais vasto alcance", reconhecendo a sua condição como privilegiada. Tendo estudado História, História de Arte e Psicologia em Bona, em 1888 passou uma temporada em Florença, onde se inicia na análise das figuras em movimento. No ano a seguir, em 1889, Warburg estuda com Hubert Janitschek e entra em contacto com a escola vienense de História de Arte. Em 1891 estuda Medicina e em 1892 presta serviço militar na cavalaria, em Karlsruhe. É em 1891 que apresenta, em Strasbourg, a tese sobre $O$ Nascimento de Vénus e A Primavera, de Boticcelli, sendo este o início de um trabalho de investigação que toma como objecto privilegiado o Renascimento e a sobrevivência (Nachleben) da Antiguidade. Este estudo será posteriormente publicado, em 1893. Nele, Warburg confronta-se com os limites de uma história de arte "estetizante" e "formal", que resulta de uma abordagem meramente erudita de estilos e avaliação estética ${ }^{3}$, propondo um novo modelo de abordagem da história de arte. Disso nos dá conta, não só Dudi-Huberman, naquele que é um estudo marcante sobre a obra de Warburg, mas também Giorgio Agamben, no seu ensaio "Aby Warburg et la Science sans nom":

\footnotetext{
${ }^{1}$ Nunca será excessivo evocar o modo como Goethe e o seu pensamento morfológico marcou profundamente estes autores e a seu modo de pensar o fenómeno enquanto manifestação da forma originária. Se Walter Benjamin é um assumido herdeiro de Goethe e do seu pensamento, perante o qual tem uma dívida no modo como pensa a origem e o fenómeno originário, a imagem dialéctica, em Aby Warburg ele encontra-se bem presente na questão da "reactivação" das imagens.

${ }^{2}$ Traduzido por "homem de letras", habitualmente.

${ }^{3}$ Nesse sentido, Warburg e Walter Benjamin aproximam-se, do ponto de vista da análise estética, recusando esse formalismo estético e procurando uma perspectiva que dê conta da vida das formas e dos géneros estéticos.
} 
A essência do ensinamento e do método de Warburg (...) identifica-se na recusa do método estilístico-formal que domina a história de arte no final do século XIX e no deslocamento do ponto central da investigação: da história dos estilos e da avaliação estética aos aspectos programáticos e iconográficos da obra de arte, tal como eles resultam do estudo das fontes literárias e do exame da tradição cultural. (AGAMBEN, 2006, p. 107)

Dessa recusa também nos fala Ernst Gombrich, que foi director do Instituto Warburg, quando refere uma "franca repulsa" pela história de arte que se orienta para um paradigma "estetizante" (GOMBRICH, 1987, p. 88). O termo é utilizado pelo próprio Warburg, numa nota inédita de 1923. Na verdade, o que o historiador pretende é ultrapassar as limitações da história de arte, que ele considera prisioneira de uma consideração puramente formal da imagem e abri-la à leitura e interpretação das imagens, em que a forma é, a seus olhos, indissociável do seu conteúdo.

Foi no "semestre de Verão" de 1927 que Aby Warburg decidiu consagrar o seu tempo ao estudo de Burckhardt e à sua obra histórica, deixando bem claras as razões pelas quais tanto Burckhardt como Nietzsche Ihe interessavam: para Warburg, eles eram verdadeiramente historiadores, não como os mestres de um tempo que havia sido explicado, mas sobretudo como sujeitos de um tempo implicado (DIDI-HUBERMAN, L'Image Survivante, 2002, p. 117). Para o historiador, eles representavam os "receptores", os "captadores" (Auffänger) da vida histórica.» (ibidem), em suma, os "sismógrafos" do seu tempo. Nesse seminário, Warburg faz uso de uma metáfora geológica usada pelo próprio Burkhardt, falando dessa inquietação que constitui a apreensão histórica:

Nós devemos reconhecer em Burkhardt e em Nietzsche os receptores de ondas mnemónicas (als Auffänger der mnemischen Wellen) e compreender como a consciência do mundo (Weltbewusstsein) afecta cada um deles duma maneira diferente. Nós devemos tentar fazer de maneira a que cada um ilumine o outro e que esta reflexão nos ajude a compreender Burkhardt como sofrendo a prova (als Erleider) da sua própria profissão [de historiado]. Os dois são sismógrafos muito sensíveis (sehr empfindliche Seismographen) em que as bases tremem quando recebem e transmitem as ondas [de choque, de memória]. (DIDI-HUBERMAN, L'Image Survivante, 2002, p. 118)

Aby Warburg assumiu para si esta condição, ao contribuir para a análise do que deve ser o papel do historiador. Mais do que um leitor ou um intérprete do passado, ele configura uma forma de viver implicada na sua época e a sua percepção dos fenómenos históricos é reveladora dessas ondas de choque subterrâneas que a atravessam. 
Um dos aspectos que mais marcaram o pensamento de Warburg foi, não apenas a presença do paganismo e o modo como ela impregna a cultura e a arte ocidentais, como também o próprio mito e a magia, que configuram a sua singular visão, contribuindo para uma dimensão mais complexa da análise da imagem, no sentido em que convoca dimensões mais ligadas à experiência afectiva, tal como ressalta a dimensão psicológica da cultura. Nas suas "Notas Inéditas para a Conferência de Kreuzlingen sobre "O Ritual da Serpente", ele refere, enquanto princípio metodológico para compreender a importância da articulação dinâmica entre imagens e estruturas culturais, modos de pensar, etc., a exigência de uma "psicologia dos modos de expressão humana" (MICHAUD, 2012, p. 265), modelo esse que terá a sua expressão na biblioteca warburguiana e, em particular, na obra Bilderatlas Mnemosyne.

A esse propósito devemos lembrar a viagem de Aby Warburg entre 1895 e 1896, pela América e onde passou algum tempo, em particular no Arizona e no Novo-México, tendo estudado os rituais dos índios Hopis. Não foi apenas a presença do ritual e da magia que imprimiu uma orientação nova no trabalho de Warburg (e que mais tarde será nele incorporada), mas também a questão da relação entre o símbolo e a imagem, através do contacto de Warburg com as teorias de Richard Semon (GOMBRICH, 1987, p. 242). Este dizia:

(...) a memória não é uma propriedade da consciência, mas a qualidade que distingue o vivo da matéria inorgânica. Ela é a capacidade de reagir a um acontecimento durante um certo tempo; ou seja, uma forma de conservação e de transmissão de energia, desconhecida do mundo físico. Cada acontecimento agindo sobre a matéria viva deixa aí um vestígio, que Semon chama engrama. A energia potencial conservada neste engrama pode ser reactivada e descarregada em certas condições. Pode-se dizer que o organismo age duma certa maneira porque ele se lembra do acontecimento precedente.

É essa a razão pela qual Warburg fala dos símbolos como sendo portadores de uma carga energética, como "dinamogramas" que são transmitidos aos artistas num estado de tensão elevada ao máximo, mas que não são polarizadas quanto à sua carga genética (GOMBRICH, 1987, pp. 248-249). A polarização dá-se - na sua carga negativa ou positiva quando há um reencontro de uma nova época e das suas necessidades vitais, podendo causar uma reinversão completa da significação, isto é, "só o contacto com a nova época produz a polarização". Tal concepção constitui o pressuposto de onde Warburg parte, para 
explicar a "vida póstuma" das imagens e dos símbolos, no sentido em que essa mesma polarização possui o poder da reactivação. O símbolo situar-se-ia assim, de acordo com Warburg, numa esfera intermediária entre a consciência e a reacção primitiva, trazendo em si a possibilidade de uma regressão como também a de um conhecimento mais elevado, uma espécie de "intervalo" ou de "terra de ninguém" no centro da própria experiência humana. E, como nos explica Giorgio Agamben:

(...) da mesma forma que a criação e a fruição da arte requerem a fusão de duas atitudes psíquicas que habitualmente se excluem mutuamente ("um abandono de si apaixonado e uma fria e distante serenidade na contemplação ordenadora"), a "ciência sem nome" procurada por Warburg é, como ele o diz numa nota de 1929, "uma iconologia do intervalo", ou uma psicologia do "movimento pendular entre a posição das causas como imagens e a sua posição como signos" (AGAMBEN, 2006, pp. 115-116).

A força simbólica do pensamento nasce dessa tensão, aproximando-se a concepção warburguiana da ideia de "arquétipo" de Jung, ainda que o seu nome jamais apareça nas notas de Warburg. A presença da componente mítica no pensamento, neste sentido de uma imagem primordial, que em Jung aparece como "inconsciente colectivo", também se encontra presente em Warburg, bem como a magia, a qual desempenha uma função central na sua teoria. Quando este fala das divindades astrológicas dos calendários alemães do tempo da Reforma, refere uma "constituição primitiva da alma, unitária e de amplo alcance." (WARBURG, Gesammelte Schriften, 1932, pp. 491-492). Nesse mesmo texto designa a lógica como aquilo "que cria o espaço do pensamento entre o homem e o objecto por intermédio da designação conceptualmente separadora", enquanto a magia "volta precisamente a destruir esse espaço de pensamento", pela união integradora do homem e objecto.

Num acutilante texto de José Miranda Justo, o autor salienta que é precisamente essa polaridade entre lógica e magia que define o horizonte a partir do qual se deve considerar a visão warburguiana do mito. É essa polaridade que permite uma convergência numa "mesma "constituição primitiva (ou estado primitivo) da alma" (JUSTO, 2012, p. 52). O astrólogo, referido por Warburg, "consegue exercer em simultâneo duas práticas, a prática abstracta de determinar o espaço ("medir") e a prática concreta de fazer, de produzir, a união entre os homens e aquilo que os rodeia ("acção mágica")" (idem). Sem, no entanto, explicitar como se produz essa convergência, ela produz-se "exactamente na medida em que haja de um dos lados um factor capaz de desencadear essa produção." (Ibidem). Detemo- 
nos na análise da produção deste dispositivo operatório para compreender o conceito warburguiano de "Nachleben", explicável a partir da magia. Isto é, como uma "vida" que se renova e se perpetua, produzindo-se para além de todos os condicionalismos que a sujeitam, graças ao seu impulso energético de vida, num sentido, precisamente, de energueia e que se traduz em aspiração à união. E este anseio corresponde à experiência concreta da separação e que é a experiência do sofrimento 4 .

A polaridade entre lógica e magia desdobra-se em três níveis distintos, como nos mostra José Miranda Justo no seu ensaio. O que permite configurações distintas dessas instâncias e faz ressaltar a intensidade operatória desses conceitos no seio da teoria warburguiana. A força da magia, enquanto parte que integra o mito, é a da destruição da separação que a lógica trata de instituir, uma resistência activa e que subsiste face ao poder analítico e separador da lógica. E esse poder, também ele vem da primitividade, procurando levar a cabo o rasgão ou a fissura que está na base da tragédia da humanidade. Todavia, a magia, com o seu poder de resistir à separação, encontra sempre modos e formas de responder ao sofrimento da separação, irrompendo como energia viva, como fluxo, no seio dessa tragédia. Warburg fala de um "combate sem tempo" no tempo. Uma luta que transcende o tempo histórico, pela forma como a repetição se inscreve e produz novas formas e configurações. No entanto, esse combate é também uma garantia de um equilíbrio de forças que se regulam entre si.

A polaridade entre lógica e magia rompe com o paradigma da linearidade da história e do seu fluxo temporal contínuo, não propondo uma abolição do tempo - o que seria contraditório - mas defende, antes, a ideia de um permanente regresso, isto é, "um tempo de retorno perpétuo" (JUSTO, 2012, p. 54), algo próximo do "eterno retorno do idêntico" de Nietzsche, numa proposta de renovada continuação da tragédia da cultura (idem). Por outro lado, a vida das imagens, segundo a proposta de Warburg, aproxima-se também do modelo de Walter Benjamin, quando este propõe a categoria da "imagem dialéctica" para a compreensão da história.

II

\section{Aby Warburg e Walter Benjamin: a legibilidade da memória}

\footnotetext{
${ }^{4}$ Aby Warburg refere-se a esta experiência nas suas notas para a Conferência de Kreutzlingen, de 1923.
} 
A proximidade entre Aby Warburg e Walter Benjamin coloca-se a vários níveis, ainda que nunca se tenham aproximado. Por sentir uma afinidade com o pensamento de Warburg, Benjamin tentou aproximar-se, através de Hofmannsthal, numa carta que Ihe escreveu em Outubro de 1926, (BANJAMIN, 1993, pp. 437-438), pedindo-Ihe que chamasse a atenção do seu círculo (e não só de Aby Warburg) para o seu trabalho sobre o Trauerspiel barroco, sobretudo no seu capítulo sobre a melancolia. A questão que poderia interessarIhes (também a Fritz Saxl e a Erwin Panofsky) era precisamente a da melancolia, pela forma como os dois historiadores haviam trabalhado sobre a obra de Dürer, "Melancolia", num texto de 1923. Mais tarde, seria o seu amigo Scholem a interceder por Benjamin, numa aproximação a Saxl, o que também viria a revelar-se complicado, resultando finalmente no falhanço da tentativa de aproximação de Benjamin e num azedume da parte deste relativamente ao círculo de Warburg, história que foi recentemente reconstituída por Sigrid Weigel (WEIGEL, 2013).

Ainda que o "renascimento" warburguiano seja posterior ao benjaminiano, é interessante ressaltar a ironia histórica que subverteu a ordem, tendo sido a partir de Benjamin que se deu o renascimento de Warburg. Foi sobretudo Wolfang Kemp (e não a biografia de Gombrich, que teve pouco impacto na altura em que foi publicada) quem veio reavivar os estudos sobre Aby Warburg (KEMP, 1975), estabelecendo afinidades e passagens com Walter Benjamin. Outro autor que veio reavivar os estudos de Warburg foi Georges Didi-Huberman, que analisa afinidades entre os dois autores, sob vários aspectos, em várias obras suas.

Uma das relações mais interessantes que Kemp refere é aquela que se pode estabelecer entre os projectos de Aby Warburg (Bilderatlas) e a obra de Benjamin Passagenwerk. Se, por um lado, se tratam de projectos inacabados, não é esse, todavia, o aspecto que mais os aproxima, mas sim o método utilizado por ambos: a montagem. Em Aby Warburg, a montagem é feita a partir de imagens e, em Benjamin, é feita a partir de citações. A ideia subjacente é a de uma reconstrução cultural que se encontra presente nos dois autores. Não é só essa compreensão da história (da história de arte em Warburg), mas também a de certas temáticas que Ihes são afins, como a ideia de suspensão, do movimento/curso da história, a questão do mito (como vimos atrás e que, em Benjamin, também se apresenta como imagem, arquétipo jungiano), o entrelaçamento entre a 
imaginação, razão e memória e o modo como ambos operam com os conceitos de imagem e de palavra, o desejo de redenção do passado e a visão crítica da técnica, por oposição à dimensão do mito.

Uma das relações mais fortes entre ambos, não só estabelecida por Kemp mas também por Didi-Huberman ${ }^{5}$ é justamente entre o conceito warburguiano de Pathosformel e o conceito de imagem dialéctica ${ }^{6}$, utilizado como uma das categorias fundamentais benjaminianas. Confrontamo-nos com ela ao longo de toda a sua obra O Livro das Passagens, sobretudo na Letra N (BENJAMIN, Gesammelte Schriften V, 1972), em que o autor reflecte sobre a teoria do conhecimento e a teoria do progresso, sendo essa, também, uma categoria fundamental nas suas Teses, em Sobre o Conceito de História (BENJAMIN, Über den Begriff der Geschichte, 1977).

Sendo o instrumento fundamental da sua teoria do conhecimento histórico, a imagem dialéctica é, no entanto, uma das mais enigmáticas e complexas do seu pensamento. Por outro lado, ela nunca foi desenvolvida de forma sistemática, conhecendo uma evolução a partir do conceito de origem (Ursprung), o qual aparece no Trauerspiel barroco, e tropeçamos em algumas ocorrências do conceito nos seus materiais preparatórios para as suas teses. Nesse texto, em particular nos materiais preparatórios para as Teses, Benjamin refere-se à imagem dialéctica como "um raio esférico que percorre todo o horizonte do passado" (BENJAMIN, Gesammelte Schriften I, 3, 1972, p. 1233). E refere-se a ela como o momento em que ocorre o conhecimento histórico ou uma "explosão", na medida em que faz deflagrar o continuum da história e a liberta da sua linearidade. Liberta-a também do modelo da temporalidade causal que estabelece a ligação do presente com o passado. A imagem dialéctica cria, assim, uma história que não é cronológica, mas sim figurativa (Bildlich), recorrendo à rememoração, enquanto operação resgatadora do

\footnotetext{
${ }^{5}$ Didi-Huberman dá início a um estudo mais sistemático a partir de 2000 e em que o autor parte da análise da imagem dialéctica benjaminiana, em Devant le Temps, Les éditions de Minuit, Paris, 2000. Esse estudo pode ser considerado embrionário, no sentido em que será, depois, alargado e os seus conceitos aplicados à análise d imgem warburguiana. Todavia, aquela que é considerada a sua obra mais sistemática sobre Warburg é L'Image Survivante, Histoire de l'Art et Temps des Fantômes selon Aby Warburg, Les éditions de Minuit, Paris, 2002.0

6 Ver, a este propósito, o ensaio de Guerrelro, António, "O Pathosformel e a imagem dialéctica: correspondências entre Warburg e Benjamin", in Mendes, Anabela, Matos Dias, Isabel, Justo, José M., Hanenberg, Peter, "Qual o tempo e o movimento de uma elipse?", Editora da Universidade Católica Portuguesa, Lisboa, 2012, pp. 70/79. É importante ressaltar o contributo de António Guerreiro para a recepção da obra de Aby Warburg em Portugal e também no Brasil. Uma boa parte do interesse sobre Aby Warburg em Portugal se deve a este autor. Também o Colóquio Internacional de 2012, em Lisboa, em torno da obra de Warburg contribuiu bastante para a sua divulgação.
} 
passado, num sentido revolucionário (e não teológico, ainda que haja uma transposição da categoria messiânica para o domínio laico).

A rememoração, de acordo com Benjamin, diz-nos que o passado não se completou. A refutação a Horkheimer, que defendia que a história está "acabada" e que é idealista pensar-se que ela é inacabada 7 , é clara, nesta passagem de Walter Benjamin:

Far-se-á uma correcção a estas reflexões, a pensar que a história não é somente uma ciência, mas também uma forma de rememoração. O que a ciência "constatou", a rememoração pode modificar. A rememoração pode transformar o que é inacabado (a felicidade) em qualquer coisa de acabado e o que é acabado (o sofrimento) em qualquer coisa de inacabado. (BENJAMIN, Gesammelte Schriften V, 1972, pp. 588, 589).

E é precisamente pela "dialéctica em suspensão", criada pela imagem dialéctica nesse "salto de tigre para o passado", ou seja, o instante em que a imagem dialéctica, através da rememoração, permite o resgate do passado, a partir do presente, formando uma constelação: "Não é que o passado lance a sua luz sobre o presente ou o presente sobre o passado. Uma imagem, pelo contrário, é aquilo em que o Outrora encontra o Agora para formar uma constelação." (BENJAMIN, Gesammelte Schriften V, 1972, pp. 577, 578).

Esta ideia da constelação é definida por Benjamin como a imagem dialéctica, como estado de suspensão da história: "a imagem é a dialéctica em suspensão. Porque, ao passo que a relação do presente com o passado é puramente temporal, a relação do Outrora com o Agora é dialéctica." (idem). Ela - a imagem dialéctica - faz deflagrar totalmente a relação temporal (no sentido cronológico) com o passado. A relação do passado com o presente é dialéctica, "imaginal" e, podemos ainda dizer, "só as imagens dialécticas são imagens autenticamente históricas, isto é, não-arcaicas." (Idem). É a imagem - entenda-se dialéctica que confere o poder da legibilidade histórica ao historiador, esse "agora da cognoscibilidade", pelo poder da rememoração. Isto é, esta contém em si o poder de actualizar o passado, através da leitura da imagem (BENJAMIN, Gesammelte Schriften V, 1972, p. 577). Ou seja, as imagens possuem uma potencialidade ou um "índice histórico", que nos diz que elas não apenas pertenceram a uma época determinada, como também só se tornam legíveis numa determinada época: "A marca histórica das imagens não indica apenas que elas pertencem a uma determinada época, mas indica sobretudo que elas não

\footnotetext{
7 Benjamin refere-se, aqui, a uma carta de Horkheimer, datada de Março de 1937. A resposta de Benjamin à posição de Horkheimer pode encontrar-se no Livro das Passagens, na passagem [N 8, 1].
} 
alcançam a legibilidade senão numa determinada época." (Idem) Por isso, o historiador é o que tem a capacidade de ler as imagens ou, dizendo de outro modo, "ler o que nunca foi escrito" e que se deixa vislumbrar pela rememoração e pela possibilidade de "reactivação" do potencial das imagens.

A relação entre o trabalho do historiador e o do alegorista, bem como o do filólogo, encontram-se de tal modo entrelaçados que se torna difícil, senão impossível, destrinça-los, sendo na linguagem que a história se apresenta, também. Se, por um lado, a imagem dialéctica é condição de abertura e de leitura da história, ela também é, por outro, uma "imagem de sonho", ideia que Benjamin explora e desenvolve n'O Livro das Passagens, nomeadamente na Letra K. Essa concepção, que Benjamin bebe tanto na psicanálise de Jung como no surrealismo, configura-se como o contexto de análise das fantasmagorias do século XIX e é assumida por Benjamin como condição do historiador quando Benjamin cita Michelet: "Cada época sonha com a seguinte" (BENJAMIN, Gesammelte Schriften V, 1972, p. 46). Essa natureza da imagem dialéctica revela-se, tal como em Warburg, como a expressão de uma polarização da imagem e é a carga "explosiva" e revolucionária da sua energia que liberta a história, despertando o que há nela de inconsciente e ainda-não-sabido.

Tal como Walter Benjamin pensou a história, a partir da categoria operatória de imagem dialéctica, foi de forma correspondente que Warburg procurou, a partir do conceito de Pathosformel, uma representação também "imaginal" da história de arte e é precisamente através delas, como médium, que construiu, pelo método da montagem, o seu Bilderatlas Mnemosyne. Como já vimos anteriormente, Warburg concebe a investigação iconográfica e das imagens como uma dinamologia, que tanto Gombrich (GOMBRICH, 1987) como Agamben (AGAMBEN, 2006) esclarecem nos seus textos, a partir dos estudos de Warburg sobre o Renascimento e o modo como eles "olhavam" para a Antiguidade.

Dá-se uma polarização ou uma reactivação quando ela entra em contacto com uma nova época, em função das suas necessidades, como já havíamos visto. A noção de Pathosformel aparece no seu ensaio sobre "Durer e a Antiguidade Italiana" (1905). Ao analisar uma gravura de Dürer, nomeadamente "A Morte de Orfeu", Warburg irá sobretudo analisar a expressão dos gestos e a acentuação dos corpos e da vida em movimento. A possibilidade de acompanhar as imagens desde a Antiguidade pagã deve-se ao facto de elas permanecerem como tensão energética, isto é, da sua natureza de "engrama" que 
concentra em si essa energia. Como diz Warburg, logo na introdução à sua obra Bilderatlas Mnemosyne, "estes engramas da experiência emotiva sobrevivem como património hereditário da memória." (WARBURG, Der Bilderatlas Mnemosyne. Gesammelte Schriften, 2000 , p. 23). António Guerreiro ressalta, a partir da leitura da obra Ninfe, de Agamben, que "Os Pathosformeln sobrevivem nas imagens" porque "estão carregados de tempo, de memória histórica" (GUERREIRO, O Pathosformel e a imagem dialéctica: correspondências entre Warburg e Benjamin, 2012, p. 76), acrescentando que “A polarização em Warburg é a dialectização da imagem e da rememoração benjaminianas" (idem).

Tal como Walter Benjamin, também o afastamento do historicismo marca a posição de Warburg, pela ideia de que as imagens históricas ou as imagens que nos são transmitidas pela memória histórica, precisam de ser reactivadas, isto é, polarizadas, tornando possível a sua significação e o resgate dessa mesma significação numa determinada época. Nada mais esclarecedor do que essa correspondência entre o Atlas de Warburg e $O$ Livro das Passagens, pois se Warburg pretendia recuperar e reconstruir a memória cultural do Ocidente por imagens, Walter Benjamin também visa o mesmo objectivo, procurando resgatar a memória histórica por imagens dialécticas, concentrando estas uma polaridade que é reactivada pela sua leitura e interpretação. Nas imagens dialécticas, como escreve Walter Benjamin, o tempo aloja-se e elas estão saturadas de tempo, até à explosão (BENJAMIN, Gesammelte Schriften V, 1972, p. 578).

Em ambos os casos, em Benjamin e Warburg, a imagem comporta em si a memória de um acontecimento forte, que reenvia para experiências originárias, como uma espécie de marca ou um traço sobre os estratos mais arcaicos da consciência. É precisamente por essa razão que a imagem traz consigo uma carga energética, destruindo, a partir desse potencial a ideia de um modelo de história como narrativa, linear e contínua. Isto é, em lugar de um encadeamento causal de acontecimentos, numa lógica de continuidade linear, há "saltos", os instantes dialécticos que recompõem a ideia de história como "imaginal" ou figurativa, correspondendo a uma ideia de constelação.

Se Benjamin procurava combater essa ideia de história assente numa base narrativa, tal ideia devia-se à sua correspondência com a ideologia do progresso, que ele queria abolir, procurando uma nova forma de "escrever" e "ler" a história, valorizando a "história dos vencidos". A ideia warburguiana de uma história construída por imagens e a 
partir delas aproxima-se da benjaminiana por uma analogia na sua concepção da história. À semelhança de Benjamin, o primado da imagem determinou uma superação na dimensão exclusivamente narrativa da história e do seu discurso. Do mesmo modo, essa analogia entre os dois autores manifesta-se no poder rememorativo da imagem - em Warburg, a imagem aparece como condensação energética, possuindo um valor afectivo - que fissura a continuidade e reclama uma dimensão não-discursiva da história.

\section{Bilderatlas Mnemosyne: ler as imagens}

Warburg consagrou os últimos anos da sua vida ao seu projecto Der Bilderatlas Mnemosyne (Atlas/Álbum da memória), ao qual ele tinha dado o nome que se encontrava à entrada da biblioteca Warburg, Mnemosyne. Este permaneceu inacabado com a sua morte, em 1929, restando uma quarentena de pranchas, onde foram fixadas à volta de um milhar de fotografias. Aí, é possível reconhecer os seus temas iconográficos preferidos. Conforme nos diz Agamben:

Mnemosyne é mais do que uma orquestração, mais ou menos estruturada, dos objectivos que haviam guiado a pesquisa de Warburg durante essa época. Ele definiu-a uma vez, de forma muito enigmática, como "uma história de fantasmas para pessoas verdadeiramente adultas" (AGAMBEN, 2006, p. 117).

Agamben esclarece-nos, recordando o pressuposto da imagem, pelo seu carácter engramático e que dava à imagem o estatuto de "órgão da memória social", condensando em si uma polaridade que Ihe advinha das "tensões espirituais de uma cultura" (idem). A memória da Europa, nas suas imagens fantasmáticas, apresentava-se condensadamente na sua obra que foi construída no "atlas" de Warburg. Assim, estava explicado o nome de Mnemosyne. Tornava possível ao europeu tomar consciência da sua tradição cultural e das suas próprias contradições e aceder a uma espécie de identidade.

Warburg constrói, assim, a memória visual da cultura europeia, nas suas origens e metamorfoses ínsitas, e a relação que ele estabelece entre as imagens dispostas nas pranchas desfaz relações hierárquicas e isolantes, que conduziam a uma classificação/organização que as subalternizava entre si. Ao invés, seria através do confronto e da coexistência entre essas imagens do passado e as do presente que se tornaria possível conferir novos significados às obras artísticas, em lugar de um processo de classificação 
convencional. Warburg rejeita, desta forma, os conceitos de hierarquia cultural ou de génio artístico, propondo uma estrutura que se abre à interpretação fecunda e geradora de um novo espaço crítico, susceptível de se abrir à construção da sua identidade no presente.

Os sinais iconográficos das imagens migram ou deslocam-se através das suas transformações e conquistam novos significados, potenciadores de novas leituras. A percepção das obras de arte e das imagens abre-se a uma temporalidade inédita, mais dinâmica, pelo modo como o receptor é afectado pelo teor engramático da imagem. Com a sua natureza polarizada, a imagem oferece-se a uma leitura dos seus extremos opostos - e Warburg analisa, a este respeito, a tensão entre dionisíaco e apolíneo nas obras de Dürer procurando auscultar neles a sobrevivência das formas (Nachleben) e o deslocamento dos sinais iconográficos. Este exercício, o de procurar os sinais e de acompanhar a sua transformação, só pode captar-se por uma forma outra de conhecimento e que garante uma transversalidade ao pensamento: através da imaginação. Didi-Huberman di-lo de forma inequívoca, no seu ensaio “Lire ce que n'a jamais été écrit” (DIDI-HUBERMAN, Lire ce que n'a jamais été écrit, 2012, p. 243). Mas este modo de ligar e de re-ligar as imagens não pode ser reduzido a uma forma pessoal e gratuita, mas a um modo de descoberta que obedece a uma lógica afim da montagem (esse processo privilegiado de operar em Benjamin e Warburg, que tanto deve à descoberta do inconsciente e à tarefa da interpretação dos sonhos).

Como o diz Georges Didi-Huberman:

(...) a imaginação aceita o múltiplo (e desfruta dele). Não para resumir o mundo ou esquematizá-lo numa fórmula de subsumpção: é nisso que um atlas se distingue de todo o breviário e de todo o tratado doutrinal. (...) A imaginação aceita o múltiplo e recondu-lo sem cessar para aí descobrir novas "relações íntimas e secretas" de novas "correspondências e analogias" que serão inesgotáveis(...) (DIDI-HUBERMAN, Lire ce que n'a jamais été écrit, 2012, p. 244).

Podemos concluir que o atlas de imagens de Warburg se oferece àquilo a que Benjamin chama a legibilidade (Lesbarkeit) do mundo nas suas condições tanto históricas, como fenomenológicas e imanentes, abrindo-se a uma visibilidade das coisas e dos seus elos. Neste sentido, a legibilidade do mundo ou o acto de ler o mundo diz respeito a algo de fundamental e que se prende com o acto de conferir sentido às coisas. Trata-se de encontrar essas ligações "íntimas e secretas" que religam o mundo e as tornam pertença de uma mesma constelação, na qual o reenvio e a pertença são reguladas pelas suas 
"correspondências e analogias". O poder da leitura, que em Walter Benjamin cabe ao historiador do materialismo dialéctico, em Warburg pertence ao historiador de arte, definese a partir dos poderes de semelhança que nos aparecem de forma inconsciente. Neste sentido, Didi-Huberman aplica o conceito de "aparelho de leitura" ao atlas, pois nele está contida essa potencialidade da legibilidade que possibilita a visibilidade do mundo e das coisas, a partir das imagens.

Não é por acaso que me vem à memória o conceito de legente de Maria Gabriela Llansol, a este propósito. Também o legente é, não o que se prende à continuidade da narrativa, mas aquele que lê o mundo a partir das imagens, libertando-o da cadeia do texto narrativo. No Livro das Comunidades, diz Maria Gabriela Llansol assim: "Ana de Peñalosa não amava os livros: amava a fonte de energia visível que eles constituem quando descobria imagens e imagens na sucessão das descrições e dos conceitos." (LLANSOL, 1999, p. 75). Este modo de entrar de leitura e de captar nas imagens a sua energia dá-nos conta de dois aspectos: por um lado, da percepção do carácter engramático das imagens, num sentido warburguiano e, por outro, de uma superação do acto de leitura, pela procura dos elos íntimos que religam as imagens entre si. Longe de se constituir como um leitor passivo, o legente é convocado pela imaginação e pelo seu poder mediúnico, secreto, de re-ligar o mundo e de the conferir sentido.

\section{REFERÊNCIAS BIBLIOGRÁFICAS}

AGAMBEN, G. Aby Warburg et la Science sans Nom. Dans : G. Agamben, La Puissance de la Pensée. p. 107-126. Paris: Bibliothèque Rivages, 2006.

BANJAMIN, W. Briefe I. Frankfurt am Main: Suhrkamp Verlag, 1993.

BAUDELAIRE, C. A Invenção da Modernidade (Sobre Arte, Literatura e Música). Lisboa: Relógio d'água, 2006.

BENJAMIN, W. Gesammelte Schriften I, 3. Frankfurt: Suhrkamp Verlag, 1972. Gesammelte Schriften V. Frankfurt am Main: Suhrkamp Verlag, 1972.

Über den Begriff der Geschichte. Dans: W. Benjamin, Sprache und Geschchte, Philosophische Essays. Frankfurt: Reclam.

A Modernidade. In: Obras Escolhidas de Walter Benjamin, v. 3. Lisboa: Assírio \& Alvim, 2006.

DIDI-HUBERMAN, G. Devant I'Image. Paris: Ed. de Minuit, 1990. 
Devant le Temps. Histoire de l'Art et Anachronisme des Images. Paris: Minuit, 2000. L'Image Survivante. Paris: Les éditions de Minuit, 2002.

. Atlas ou le gai savoir inquiet. L'Oeil de l'histoire, 3,. Paris: Minuit, 2011.

Lire ce que n'a jamais été écrit. Dans I. M. Anabela Mendes, Qual o Tempo e o Movimento de uma Elipse? Estudos sobre Aby M. Warburg (pp. 243-260). Lisboa: Universidade Católica, 2012. GOMBRICH, E. An Intelectual Biography. Oxford: Oxford, 1987.

GUERREIRO, A. O Pathosformel e a imagem dialéctica: correspondências entre Warburg e Benjamin. Dans I. M. Anabela Mendes, Qual o tempo e movimento de uma elipse? Estudos sobre Aby Warburg (pp. 71-81). Lisboa: Universidade Católica, 2012.

Aby Warburg e os Arquivos da Memória. Récupéré sur Enciclopédia e Hipertexto: www.educ.fc.ul.pt/hyper/warburg.htm, s/d.

JUSTO, J. M. Ernst Cassirer e Aby Warburg. Alguns apontamentos em torno da questão do mito. Dans I. M. Anabela Mendes, Qual o tempo e o movimento de uma elipse? Estudos sobre Aby Warburg. Lisboa: Universidade Católica, 2012.

KEMP, W. Kritische Berichte. Récupéré sur http://archiv.ub.uni-heidelberg.de/artdok/2287/ , 1975.

LLANSOL, M. G. O Livro das Comunidades. Lisboa: Relógio d'água, 1999.

MICHAUD, P. A. Aby Warburg et l'image en mouvement. Paris: Macula, 2012.

SOEIRO, R. G. O Segundo Sol Negro: George Steiner e A. Warburg em órbitas elípticas. Dans I. M. Anabela Mendes, Qual o tempo e o movimento de uma elipse? Estudos sobre Aby Warburg. Lisboa: Universidade Católica de Lisboa, 2012.

WARBURG, A. Gesammelte Schriften. Berlin-Leipzig: Akademie Verlag, 1932.

Der Bilderatlas Mnemosyne. Gesammelte Schriften, v. II, 1. (M. a. Brink, Éd.) Berlin: Akademie Verlag, 2000.

. Die Erneuerung der heidnischen Antike. Kulturwissenchaftliche Beiträge zur Geschichte der Europäischen Renaissance. Dans A. Warburg, Gesammelte Schriften I, 1-2. Berlin: Akademie Verlag, 2000.

Atlas Mnemosyne. Paris: L'ecarquillé, 2012.

WEIGEL, S. Walter Benjamin: Images, the Creaturely, and the Holy. Stanford: Stanford University Press, 2013.

WINCKELMANN, J. J. Réflexions sur l'imitation des Oeuvres Grècques en peinture et sculpture. Paris: Aubier, 1954.

WUTTKE, D. Aby M. Warburg-Bibliographie 1866 bis 1995. Werk und Wirkung. Mit Annotationen. Baden-Baden: Valentin Koerner, 1998. 